\title{
Correction to: A Multi-Center, Open-Label, Pharmacokinetic Drug Interaction Study of Erenumab and a Combined Oral Contraceptive in Healthy Females
}

\author{
Yang $\mathrm{Xu}^{1} \cdot$ Kristin Gabriel $^{1} \cdot$ Yi Wang $^{1} \cdot$ Yanchen $_{\text {Zhou }}{ }^{2} \cdot$ Osaro Eisele $^{1} \cdot$ Apinya Vutikullird $^{3} \cdot$ Daniel D. Mikol $^{1}$. \\ Edward Lee ${ }^{1}$
}

Published online: 6 May 2019

(c) Springer Nature Switzerland AG 2019

\section{Correction to: CNS Drugs \\ https://doi.org/10.1007/s40263-019-00626-2}

An Online First version of this article was made available online at http://link.springer.com/journal/40263/onlineFirst/ page/1 on 8 April 2019. An error was subsequently identified in the article, and the following correction should be noted:

Section 2.3 (Trial Design), sentence 2- the text that read:

During the study, subjects received three 28-day cycles of daily combined oral contraceptive (21 days of ethinylestradiol $0.025 \mathrm{mg} /$ norgestimate $0.25 \mathrm{mg}$ followed by inert ingredients for 7 days) (Fig. 1).

Should read:

During the study, subjects received three 28-day cycles of daily combined oral contraceptive (21 days of ethinylestradiol $0.035 \mathrm{mg} /$ norgestimate $0.25 \mathrm{mg}$ followed by inert ingredients for 7 days) (Fig. 1).

The original article can be found online at https://doi.org/10.1007/ s40263-019-00626-2.

Yang Xu

yangx@amgen.com

1 Amgen Inc, 1 Amgen Center Dr, Thousand Oaks, CA 91320, USA

2 Amgen Inc, 1120 Veterans Blvd, South San Francisco 94080, CA, USA

3 WCCT Global, Cypress, CA, USA 